\title{
Exchange of carbonyl sulfide (COS) between wheat soil and atmosphere
}

\author{
MU Yujing (牟玉静), ZHANG Xiaoshan (张晓山) \& SONG Wenzhi (宋文质) \\ Research Center for Eco-Environmental Sciences, Chinese Academy of Sciences, Beijing 100085, China \\ Correspondence should be addressed to Mu Yujing (email: yujingmu@yahoo.com)
}

Received March 22, 2001

\begin{abstract}
The exchange of COS between wheat soil and atmosphere was investigated by using a dynamic enclosure. The investigated soil type acted as a significant sink for the trace gas coS. Atmospheric COS mixing ratios and temperature were found to be the physicochemical parameters controlling the uptake. The uptake reached maximum about $0.6 \times 10^{-12} \mathrm{~mol} \cdot \mathrm{g}^{-1} \cdot \mathrm{h}^{-1}$ at $15-$ $20^{\circ} \mathrm{C}$ under natural ambient atmospheric conditions. The measured uptake values agree well with that calculated by Guenther algorithm.
\end{abstract}

Keywords: COS, wheat soil, uptake.

Carbonyl sulfide (COS) nearly inert to photochemical decomposition in the troposphere is the most abundant reduced sulfur gas in the atmosphere. The natural ambient mixing ratio is $(22.32 \pm 4.46) \times 10^{-12} \mathrm{~mol} / \mathrm{L}^{[1,2]}$. COS can be transported into the stratosphere, where it is oxidized to sulfate serving as an important source for the stratospheric aerosol layer. The stratospheric sulfate aerosol layer can influence the earth's radiation budget and plays an important role in the heterogeneous reaction chemistry leading to ozone destruction ${ }^{[3,4]}$. It is still unclear about the sources and sinks of COS at present, e.g. the imbalance of the global budget of $\operatorname{COS}^{[5]}$.

Vegetation is the major tropospheric sink of COS with sink strength of $0.16 \times 10^{12}-0.91 \times$

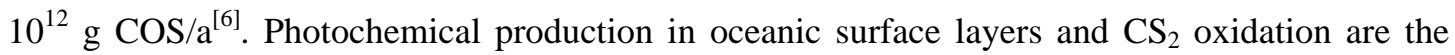
sources of $\operatorname{COS}^{[1,2]}$. Soils were previously considered to represent one of the dominant sources of COS, however, recently published field studies present convincing evidence that soils act better as a sink than a source for $\operatorname{COS}^{[1]}$. The earlier studies usually used COS-free air for purging the soil enclosures and in this way the uptake capability of soils was masked. Andreae et al. ${ }^{[5]}$ recently proposed to regard soils globally as a COS sink instead of a source, which leads to an obviously more balanced global budget of sinks and sources.

As outlined above, there is a clear need for a better understanding of the role of soils as an important sink for COS and consequent impact on the global COS budget. In this study, the exchange of COS between wheat soil and the atmosphere was studied under controlled laboratory conditions, and the wheat soil in China acting as a sink of COS was reported. 


\section{Experimental}

\subsection{Soil samples and flux determination}

Soil samples were obtained from wheat field of Shigezhuang Farm, Beijing, taken from the top $5 \mathrm{~cm}$ and sieved with a stainless steel sieve (mesh width $3 \mathrm{~mm}$ ), then stored in a polyethylene bag at $3^{\circ} \mathrm{C}$ until the trace gas flux investigations.

The measurements were performed with $200 \mathrm{~g}$ of the soil in a dynamic enclosure which was installed inside a super thermostat under controlled temperature, constructed of glass jar with ID $13.6 \mathrm{~cm}$, length $9 \mathrm{~cm}$, and volume $2.9 \mathrm{~L}$. Total airflow through the enclosure was $0.697 \mathrm{~L} / \mathrm{min}$. To prevent the soil samples from drying during the experiments, the air was humidified by bubbling through a water bottle placed inside the super thermostat at the same temperature as the enclosure.

The uptake data $\left(F_{\text {flux }}^{\mathrm{COS}}, \mathrm{pmol} \cdot \mathrm{g}^{-1} \cdot \mathrm{h}^{-1}\right)$ were calculated as the concentration difference $(\mathrm{mol} / \mathrm{L})$ between the inlet and outlet of the enclosure, the dry weight of the soil samples $(W, \mathrm{~g})$, and the air flow rate $\left(F_{\text {air }}, \mathrm{L} / \mathrm{min}\right)$ :

$$
F_{\text {flux }}^{\mathrm{COS}}=\left(\left(C-C_{0}\right) \times 60 \times F_{\text {air }}\right) /(22.4 \times W) .
$$

\subsection{Sampling and analysis of COS}

COS was analyzed on a gas chromatograph (GC-6A, Shimadzu) equipped with a flame photometric detector. The glass column (2 $\mathrm{m} \times 4 \mathrm{~mm}$ ) packed with 20\% SE-30 on Chromosorb $\mathrm{P}$ (60 - 80 mesh) was selected as separation column. The column temperature, injection temperature and detector temperature were 70,140 and $240{ }^{\circ} \mathrm{C}$, respectively. Typical gas flow rates were: $\mathrm{Ni}$ trogen (carrier gas, 99.999\%), $30 \mathrm{~mL} / \mathrm{min}$, hydrogen, $40 \mathrm{~mL} / \mathrm{min}$, and air, $40 \mathrm{~mL} / \mathrm{min}$.

COS in the air sample was concentrated on Tenex-GC (60-80 mesh) by using liquid nitrogen. The adsorption tube consisted of a small tube being thick in the middle and thin at two sides. The two sides were connected with an injection needle and a three-way valve of Teflon, respectively. The thick part of the adsorption tube was filled with about $300 \mathrm{mg}$ of Tenax GC (fig. 1). Two liters of air sample collected in a sampling bag passed through the adsorption tube dipped in liquid nitrogen with a flow rate of

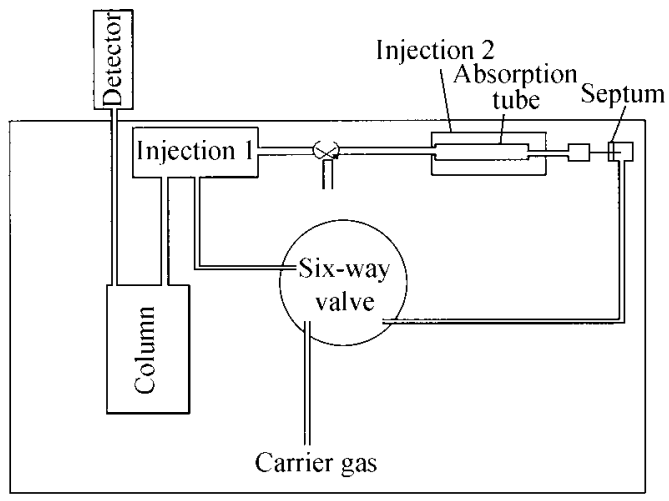

Fig. 1. GC inlet system. about $200 \mathrm{~mL} / \mathrm{min}$ by using a sampling pump. To prevent build-up of water in the Tenax trap tube at low temperature, the water was pre-trapped by means of the drying agent calcium chloride $\left(\mathrm{CaCl}_{2} \cdot \mathrm{H}_{2} \mathrm{O}\right)$. The injection method is shown in fig. 1. The adsorption tube containing COS sample was inserted in injection port 2, and the adsorbed COS was thermally liberated directly 
into the carrier gas stream (injection port temperature: $140^{\circ} \mathrm{C}$ ) and transferred to the GC column when the six-way valve was turned.

\subsection{Configuration of gas mixture}

Compressed air was purified by passing it through a three-stage gas purification system consisting of three columns with silica gel, molecular sieve and charcoal. COS concentration at the outlet of the gas purification system was found to be $(4.28 \pm 0.31) \times 10^{-12} \mathrm{~mol} / \mathrm{L}$. The concentration of COS of compressed air used in this study was $(23.62 \pm 1.43) \times 10^{-12} \mathrm{~mol} / \mathrm{L}$. COS mixing ratios in the desired ranges were obtained by mixing the purified compressed air with known gas mixtures prepared by dilution of standard COS air sample $\left(2 \%, \mathrm{COS} / \mathrm{N}_{2}\right.$, Scott Specialty Gases Inc.). All flows were regulated by mass flow controllers (Shengye Technological Development Inc., Beijing).

\subsection{Rate of recovery and error estimation}

Injecting $1 \mathrm{~mL}$ air sample containing COS $\left(8.93 \times 10^{-8} \mathrm{~mol} / \mathrm{L}\right)$ into a sampling bag containing $2 \mathrm{~L}$ purified compressed air, and concentrating the air sample onto Tanex tube as described above. Comparing the respond values between the direct injection and injection after being concentrated, the rate of recovery is $94 \% \pm 5 \%$ (20 times injections). The relative precision of the measurements was $6 \%$, based on reproducibility of consecutive samples over a 5-day period (number of replicates $n=40)$ with compressed air sample $(23.62 \pm 1.43) \times 10^{-12} \mathrm{~mol} / \mathrm{L}$. The uncertainties of the flow measurement and pressure reading (pressure gauge: 0-1333 $\mathrm{Pa}$, and 0-13332 $\mathrm{Pa}$, MKS Instrument Inc., USA) used for dilution of standard gas were estimated to be $5 \%$ and $1 \%$, respectively. The absolute accuracy was estimated to be about $10 \%$.

\section{Results and discussion}

\subsection{Uptake of COS under varying COS mixing ratios}

The exchange rate of COS between soil and the atmosphere depends on ambient concentration; the net exchange within a certain biotic system is interpreted as the result of simultaneously operating production and consumption processes ${ }^{[2]}$. This implies the existence of a so-called compensation point that is the consumption and production balancing each other under an ambient concentration, and the net flux is zero. The production rate, the deposition velocity, and the compensation point concentration are determined by the linear regression of observed fluxes versus concentrations, and are found as the ordinate intercept, the slope, and the abscissa intercept of the regression line, respectively. The mixing ratios of COS in the air flushing the enclosure varied between $4.28 \times 10^{-12}$ and $104.82 \times 10^{-12} \mathrm{~mol} / \mathrm{L}$, air temperature within the enclosure was kept constant at $(18 \pm 1)^{\circ} \mathrm{C}$, and the soil water content was $9.35 \%$. The investigated soil acted as a sink for all COS concentrations except one of $4.28 \times 10^{-12} \mathrm{~mol} / \mathrm{L}$. The data in fig. 2 show a linear increase of COS uptake with increasing the ambient COS mixing ratios. The results agree with that 
of Kesselmier et al. ${ }^{[2]}$. The results of Kesselmier et al. showed a saturation-like uptake behavior under higher COS concentration, however, there was no such a phenomenon even under much higher concentration than the maximum value of theirs in this study. The production rate, the deposition velocity, and the compensation point concentration of COS were obtained from

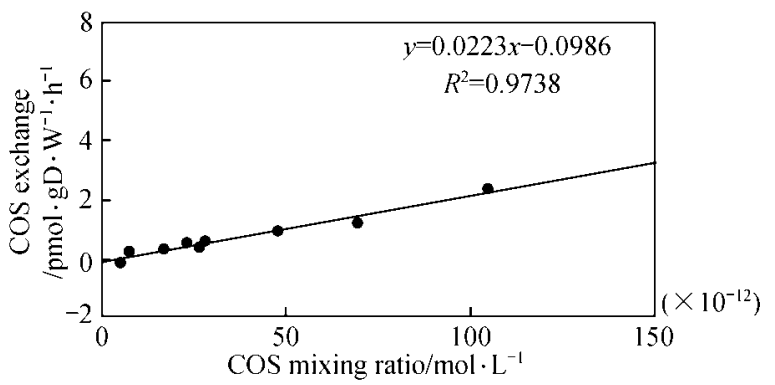

Fig. 2. COS exchange between the soil and the atmosphere at different concentrations $\left(18^{\circ} \mathrm{C}\right.$, positive sign is uptake). the linear regression as $0.098 \times 10^{-12} \mathrm{~mol} \cdot \mathrm{g}^{-1} \cdot \mathrm{h}^{-1}, 0.6 \times 10^{-12} \mathrm{~mol} \cdot \mathrm{g}^{-1} \cdot \mathrm{h}^{-1}$ (under ambient concentration of about $24.55 \times 10^{-12} \mathrm{~mol} / \mathrm{L}$ ), and $4.42 \times 10^{-12} \mathrm{~mol} / \mathrm{L}$, respectively ${ }^{[7]}$. The observed compensation point of $4.42 \times 10^{-12} \mathrm{~mol} / \mathrm{L}$ is very similar to the data obtained during field measurements on a different soil type in California, showing a compensation point below $4.46 \times 10^{-12}$ $\mathrm{mol} / \mathrm{L}^{[1]}$, but larger than $2.37 \times 10^{-12} \mathrm{~mol} / \mathrm{L}$ of Kesselmier et al. ${ }^{[2]}$. Similar values of $4.02 \times 10^{-12}$ $6.70 \times 10^{-12} \mathrm{~mol} / \mathrm{L}$ were also found for the exchange of COS between plants and the atmosphere. The production rate and the deposition velocity were less than that of Kesselmier et al. ${ }^{[2]}$, indicating that the production rate, the deposition velocity, and the compensation point concentration of COS depended on soil types. The production rate compared to the measured COS uptake in combination with the compensation point clearly shows that the investigated soil type can hardly emit COS in nature. The filed measurement of Cao et al. ${ }^{[8]}$ at the same site in this study indicated that the soil acted as a source of COS. Although they used ambient air for flushing their enclosure, their results were contrary to the recent investigations ${ }^{[1,2]}$. The concentration of COS of compressed air they measured was $51.34 \times 10^{-12} \mathrm{~mol} / \mathrm{L}^{[9]}$, which is about twice as great as the actual COS concentration in the atmosphere. So we suspected the reliability of their results.

\subsection{Uptake of COS under varying temperatures}

Temperature has a significant influence on chemical and biological reactions. The COS uptake by the soil therefore was determined under varying temperatures $\left(0-30^{\circ} \mathrm{C}\right)$ by using com-

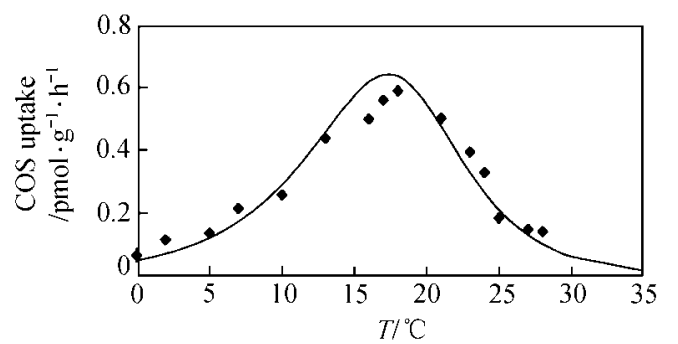

Fig. 3. COS uptake at different temperatures. The plotted line gives the mathematical approximation according to the algorithm of Guenther et al. pressed air $(23.62 \pm 1.43) \times 10^{-12} \mathrm{~mol} / \mathrm{L}$ as flushing gas. The results are shown in fig. 3. The uptake increases with temperature up to an optimum between 15 and $20^{\circ} \mathrm{C}$ ( maximum value of about $0.6 \times 10^{-12} \mathrm{~mol} \cdot \mathrm{g}^{-1} \cdot \mathrm{h}^{-1}$ ), followed by a sharp decrease at higher temperatures. This agrees well with that of Kesselmier et al. ${ }^{[2]}$, but the maximum value is about five times less than that of Kesselmier et al. ${ }^{[2]}$. 
The exchange of COS between soil and atmosphere is associated with enzymatically catalyzed process, while temperatures have impact on the activity of enzyme. An algorithm taking account of an enzymatic behavior for process description ${ }^{[10]}$, simplified by Guenther et al. ${ }^{[11]}$ to describe isoprene emission from plants, was in this case empirically adapted to outline the COS exchange dependence on temperature. Thus the exchange at a given temperature $F_{T}$ is described as a function of a standard exchange factor $F_{0}$ multiplied by a temperature correction factor $\varphi(T)$. Empirical coefficients adopted that of Kesselmier et al. ${ }^{[2]}$. The standard temperature was defined as $25^{\circ} \mathrm{C}$.

$$
F_{T}=F_{0} \varphi(T)
$$

where $F_{T}$ is COS exchange rate at temperature $T\left(10^{-12} \mathrm{~mol} \cdot \mathrm{g}^{-1} \bullet \mathrm{h}^{-1}\right), F_{0}$ COS exchange rate at standard temperature $T\left(10^{-12} \mathrm{~mol} \cdot \mathrm{g}^{-1} \cdot \mathrm{h}^{-1}\right)$, and $\varphi(T)$ empirical correction factor for temperature, which is defined by

$$
\varphi(T)=\frac{\exp \frac{\kappa_{T_{1}}\left(T\left({ }^{\circ} \mathrm{C}\right)-T_{\mathrm{S}}\left({ }^{\circ} \mathrm{C}\right)\right)}{R T_{\mathrm{S}}(\mathrm{K}) T(\mathrm{~K})}}{1+\exp \frac{\kappa_{T_{2}}\left(T\left({ }^{\circ} \mathrm{C}\right)-\kappa_{T_{3}}\right)}{R T_{\mathrm{S}}(\mathrm{K}) T(\mathrm{~K})}},
$$

where $T\left({ }^{\circ} \mathrm{C}\right)$ and $T(\mathrm{~K})$ are actual temperature $\left({ }^{\circ} \mathrm{C}\right.$ and $\left.\mathrm{K}\right), T_{\mathrm{S}}\left({ }^{\circ} \mathrm{C}\right)$ and $T_{\mathrm{S}}(\mathrm{K})$ are standard temperatures $\left({ }^{\circ} \mathrm{C}\right.$ and $\left.\mathrm{K}\right), R$ is molar gas constant $\left(8.31 \mathrm{~J} \cdot \mathrm{K}^{-1} \cdot \mathrm{mol}^{-1}\right), \kappa_{T_{1}}$ is empirical coefficient $\left(1167818.31 \mathrm{~J} \cdot \mathrm{K}^{-1} \cdot \mathrm{mol}^{-1} \cdot{ }^{\circ} \mathrm{C}^{-1}\right), \quad \kappa_{T_{2}}$ is empirical coefficient $\left(312219.8 \mathrm{~J} \cdot \mathrm{K}^{-1} \cdot \mathrm{mol}^{-1} \cdot{ }^{\circ} \mathrm{C}^{-1}\right)$, and $\kappa_{T_{3}}$ is empirical coefficient $\left(18.449^{\circ} \mathrm{C}^{-1}\right)$.

$F_{0}$ can be obtained from the experimental data, and the exchange rate $\left(10^{-12} \mathrm{~mol} \cdot \mathrm{g}^{-1} \cdot \mathrm{h}^{-1}\right)$ at different temperatures was drawn from the algorithm. The simulated result is shown as the plotted line in fig. 3. It is obvious that the measured data are well fitted by the algorithm.

\section{Conclusion}

The results of this study indicate that wheat field soil acted as a sink of COS. The uptake rate of COS by soils depended on the ambient concentration of carbonyl sulfide, soil types, soil temperature and so on. To accurately evaluate the impact of COS on global environment, wide investigation of mixing ratios of COS in different areas and for different seasons, and of deposition rates of COS on different soils are needed.

Acknowledgements This work was supported by the National Natural Science Foundation of China (Grant No. 29837190).

\section{References}

1. Kuhn, U., Ammann, C., Wolf, A. et al., Carbonyl sulfide exchange on an ecosystem scale: soil represents a dominant sink for atmospheric COS, Atmospheric Environment, 1999, 33: 995-1008. 
2. Kesselmier, J., Teusch, N., Kuhn, U., Controlling variables for the uptake of atmospheric carbonyl sulfide by soil, Journal of Geophysical Research, 1999, 104(D9): 11577-11584.

3. Engel, A., Schmidt, U., Vertical profile measurements of carbonyl sulfide in the stratosphere, Geophysical Research Letter, 1994, 21: 2219-2222.

4. Solomon, S., Sanders, R. W., Garcia, R. R. et al., Increased chlorine dioxide over Antarctica caused by volcanic aerosols from Mount Pinatubo, Nature, 1993, 363: 245-248.

5. Andreae, M. O., Crutzen, P. J., Atmospheric aerosols: Biogeochemical sources and role in atmospheric chemistry, Science, 1997, 176: 1052-1058.

6. Kesselmier, J., Merk, L., Exchange of carbonyl sulfide (COS) between agricultural plants and the atmosphere: Studies on the deposition of COS to peas, corn and rape seed, Biogeochemistry, 1993, 23: 47-59.

7. DeMello, W. Z., Hines, M. E., Application of static and dynamic enclosures for determining dimethyl sulfide and carbonyl sulfide exchange in sphagnum peatlands: Implications for the magnitude and direction of flux, Journal of Geophysical Research, 1994, 99: 601-607.

8. Cao, M., Zhuang, Y. H., Determination of carbonyl sulfide fluxes from soil, The atmospheric ozone variation and its effect on the climate and environment in China, 1997 (ed. Zhou, X. J.), Beijing: Meteorol. Press, 1997, 131—135.

9. Cao, M., Zhuang, Y. H., Emission factors of trace OCS from crop residues burning and estimation its amount in China, Chinese Journal of Environmental Science, 1996, 17(1): 34-36.

10. Sharpe, P., De Michelle, D., Reaction kinetics of poikilothermic development, Journal of Theory Biological, 1977, 64: $649-670$.

11. Guenther, A. B., Zimmerman, P. R., Harly, P. C., Isoprene and monoterpene emission rate variability: Model evaluation and sensitivity analyses, Journal of Geophysical Research, 1993, 98: 609—617. 